\title{
Discrimination reversal performance in squirrel monkeys as a function of prereversal experience and overlearning'
}

\author{
Henry A. Cross, teXAS TEChNOLOGICAL COLLEGE \\ Robert M. Fiekling, James B. Carpenter and Larry T. Brown, OKLAHOMA STATE UNIVERSITY
}

\begin{abstract}
Abstraet
Monkeys were given object reversal training. Variables were number of acquisition trials and type of prereversal experience. "Negative" experience benefited $S$ more than "positive" or "traditional." Reversal was more difficult as initial acquisition length was increased. A second study extended both the number of acquisition and reversal trials. Reversal trials to criterion increased as initial training was extended but results were not reliable.
\end{abstract}

\section{Problem}

In a recent study (Cross \& Brown, 1965) monkeys receiving 4 single-object information trials interspersed between discrimination and reversal profited from such experience in a 6 -trial reversal. The prereversal experience was particularly effective if it consisted of nonrewarded trials with the original positive object. These data were interpreted as supporting the primary role of avoidance in discrimination performance. An incidental finding was that reversal was easier after 6 trials than after 18 trials, a result not consonant with the overlearning reversal effect or ORE (e.g., Reid, 1953).

These two studies were designed to extend the original one. In Experiment 1, acquisition was increased to 54 trials since it was possible that overlearning was not achieved in the initial study. In addition, the negative and positive prereversal conditions were directly compared with the traditional reversal procedure. In Experiment 2 , reversal training was extended to criterion. This was necessary because overlearning may enhance reversal performance even though it retards extinction (e.g., Reid, 1953). If so, the use of a limited number of reversal trials could obscure an ORE.

\section{Experiment 1}

\section{Method}

Eight male squirrel monkeys used in the Cross \& Brown (1965) study were selected as Ss. Ss were picked because they had evidenced the greatest learning in the initial study, and it was desirable to insure maximal overlearning during discrimination. The WGTA apparatus was the same as originally employed. All Ss received 3 sequences consisting of 9 problems each. The problems were factorial combinations of 3 problem lengths $(6,18$, and 54 trials) and 3 prereversal experience conditions (positive, negative, and traditional). The positive prereversal condition consisted of 4 single- object trials with the object which had been negative during the discrimination. The trials were rewarded and were administered from the center food well. Conversely, for the negative condition $\mathrm{S}$ was given 4 nonrewarded trials with the object that had been positive but which was to be negative during the reversal. After the prereversal trials, Ss were given 6 reversal trials. The traditional procedure involved a single information trial with the simultaneous presentation of both objects, with reward conditons opposite from those in the discrimination trials. Subsequently, 6 additional reversal trials were given.

The order of the problems within a sequence was randomly determined for each $\mathrm{S}$. Each $\mathrm{S}$ received 1 problem daily and each sequence was accomplished successively, so that the experiment continued for 27 days. The position of the rewarded stimulus, during both discrimination and reversal, was randomly determined for each S. The only restraint was that the rewarded object occurred equally in both left and right positions. The number of correct reversal trials (trials 1 through 6 for the positive and negative conditions and trials 2 through 7 for the traditional) was totalled over the sequences and employed as the basic datum in an analysis of variance.

\section{Results and Discussion}

The negative prereversal condition resulted in more efficient reversal than either the positive or the traditional, as was evidenced by a significant prereversalcondition effect $(\mathrm{F}-=42.63 ; \mathrm{df}=2 / 14 ; \mathrm{p}<.001)$. Multiple comparisons revealed better performance following the negative condition than either the positive $(p<.001)$ or the standard $(p<.001)$. There was also a significant effect $(F=20.12 ; d f=2 / 14 ; p<.001)$ attributable to the length of the original problem. Multiple comparisons showed better performance following 6-trial problems than either 18 -trial $(p<.01)$ or 54 -trial problems $(p<$ $.001)$. Moreover, more correct reversal responses occurred following 18-trial than 54-trial problems $(p<.05)$. These findings are evident in the data, expressed in percentages, which appear in Fig. 1. The discrimination performance, disregarding only trial 1 , averaged $85 \%$ correct on the 54 -trial problems.

The finding of the initial investigation was substantiated. Negative prereversal experience was superior to positive, suggesting that discrimination is largely a matter of learning avoidance responses. When Ss were given 4 positive prereversal trials, they performed no 


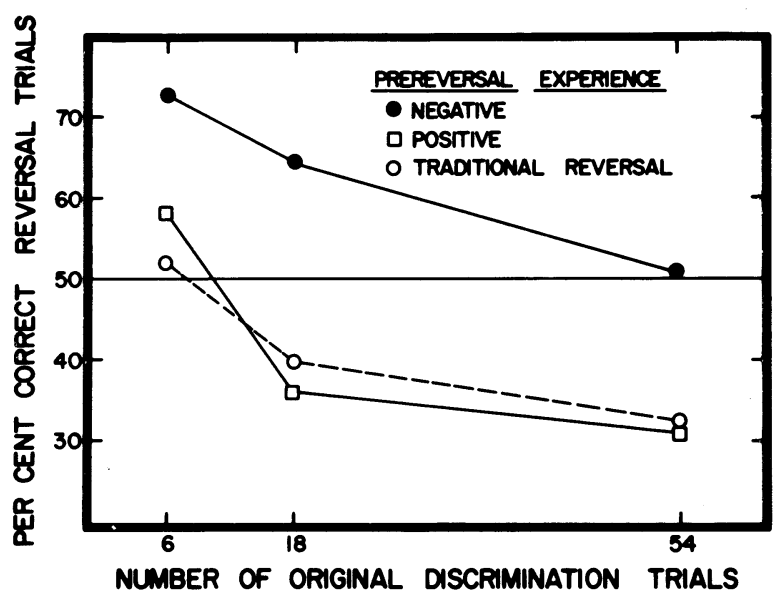

Fig. 1. Percentage of correct reversal trials with three types of prereversal experience after original training of 6,18 , or 54 trials.

better in reversal than when they received the single 2-object information trial of the traditional condition. For the 18- and 54-trial problems a preponderant number of responses during the information trial of the traditional condition were made to the incorrect stimulus. This in effect means that one nonrewarded trial has the same efficacy as four rewarded trials.

There was evidence for an effect just the opposite of the ORE. Reversal performance declined directly with an increase in initial triaks. This cannot be attributed to poor learning or lack of overlearning since the discrimination performance was high. The possibility did remain, however, that by limiting reversals to six trials the ORE did not have sufficient opportunity to become apparent.

\section{Experiment 2}

\section{Method}

The Ss and apparatus were identical to those used in Experiment 1, and the traditional reversal procedure was employed in all problems which differed only in their length: 10, 20, 40, or 80 trials. Each $\mathrm{S}$ received 6 sequences of the problems during a 24-day period.
Reversal training was extended until a criterion of 8 out of 10 correct responses was met, with the last 6 trials correct. Randomization of stimulus placement was the same as before except during reversal trials when position was randomly determined within successive blocks of 20 trials with the restriction that there be equal lefts and rights in a given block.

\section{Results and Discussion}

Mean trials to criterion for the 10-, 20-, 40-, and 80-trial conditions were, respectively, 19.27, 20.04, 22.62, and 22.96. These differences, while showing the trend of Experiment 1, were not significant $(F=1.79$; $\mathrm{df}=3 / 21 ; \mathrm{p}<.25)$. The learning during discrimination was high. When only the first discrimination trial was excluded, the percentages correct for the 10-,20-,40-, and 80-trial problems were, respectively, $78 \%, 86 \%$, $88 \%$, and $92 \%$.

While the results did not support the findings of Experiment 1 that overlearning hinders reversal performance, they also did not provide evidence for an ORE. This was true even though Ss achieved high overlearning and reversal was extended to criterion. D'Amato \& Schiff (1964) have called attention to 11 position discrimination studies in which an ORE was not observed. The 2- object discrimination studies reported here also question the generality of an ORE and point up the need for an examination of the variables which govern this phenomenon.

\section{References}

CROSS, H. A., \& BROWN, L. T. Discrimination reversal learning in squirrel monkeys as a function of number of acquisition trials and prereversal experience. J. comp. physiol. Psychol., in press.

D'AMATO, M. R., \& SCHIFF, D. Further studies of overlearning and position reversal learning. Psychol. Rep., 1964, 14, 380-382.

REID, L. S. The development of noncontinuity behavior through continuity learning. J. exp. Psychol., 1953, 46, 107-112.

\section{Note}

1. Supported in part by grant $M H$ 07482-01 from the National Institute of Mental Health. 